\title{
CRESCIMENTO INICIAL DE PLANTAS DE LICURI (Syagrus coronata (MART.) BECC.) EM DIFERENTES NÍVEIS DE LUMINOSIDADE ${ }^{1}$
}

\author{
Noeli Oliveira Santana Carvalho ${ }^{2}$, Claudinéia Regina Pelacani ${ }^{3}$, Manuela Oliveira de Souza Rodrigues ${ }^{2}$ e \\ Iara Cândido Crepaldi ${ }^{3}$
}

\begin{abstract}
RESUMO - Modificações nos níveis de luminosidade, aos quais uma espécie está adaptada, podem condicionar diferentes respostas fisiológicas em suas características bioquímicas, anatômicas e de crescimento. Este trabalho teve como objetivo avaliar o crescimento inicial de plantas de licuri (Syagrus coronata (Mart.) Becc.) submetidas a diferentes condições de luminosidade. Neste estudo foram utilizadas plântulas de licuri com cinco meses de idade, cultivadas em substrato composto de terra + adubo orgânico e mantidas a 30 e $100 \%$ de luminosidade. Mensalmente foram tomadas medidas de altura, diâmetro do colo e número de folhas das plantas, durante um período de 12 meses. Ao final do experimento, determinaram-se a massa seca, a área foliar e o teor de clorofila. O maior crescimento em altura, diâmetro do colo, número de folhas emitidas e massa seca total foram verificados nas plantas submetidas a $30 \%$ de luz. A proporção de massa seca direcionada para as raízes foi maior à medida que houve aumento da intensidade luminosa. Já a parte aérea, diferentemente do sistema radicular, apresentou uma diminuição com o aumento da luminosidade. Em 100\% de luz, as plantas apresentaram maior área foliar total, bem como maior razão das clorofilas $a / b$, enquanto a área foliar específica mostrouse inversamente proporcional à intensidade luminosa. Com os resultados obtidos, pode-se inferir que a condição de sombreamento favoreceu o crescimento inicial das plantas de licuri.
\end{abstract}

Palavras-chave: Syagrus coronata, crescimento e luminosidade.

\section{INITIAL GROWTH OF LICURI PLANTS (Syagrus coronata (MART.) BECC.) UNDER DIFFERENT LIGHT INTENSITY}

\begin{abstract}
Changes in light intensity, to which a species is adapted, may condition different physiological responses in its biochemical, anatomical and growing features. This paper aims at assessing the initial growth of licuri plants (Syagrus coronata (Mart.) Becc.) subjected to different light conditions. Five-month-old licuri plants, grown in substrates of soil + organic fertilizer, were used. Plants were kept in $30 \%$ and $100 \%$ light intensity. Measurements of height, stem diameter, and number of leaves were taken monthly over a 12-month period. At the end of the experiment, dry mass, foliar area and chlorophyll contents were evaluated. Those plants submitted to $30 \%$ light intensity showed improvement in height, stem diameter, number of produced leaves, and total dry mass. Proportion of dry mass directed towards the roots was higher as light intensity increased, however, aerial part, differently from the radicular system, decreased. Under 100\% light intensity, the plants showed a larger total leaf area, as well as a higher chlorophyll a/b ratio. Specific leaf area was inversely proportional to the light intensity. With the obtained results, it can be inferred that shade favored initial growth of licuri plants.
\end{abstract}

Keywords: Syagrus coronata, growth and light intensity.

\footnotetext{
${ }^{1}$ Recebido em 06.10.2004 e aceito para publicação em 05.04.2006.

${ }^{2}$ Programa de Pós-Graduação em Botânica, Universidade Estadual de Feira de Santana, Unidade Experimental Horto Florestal, BR 116, km 03, 44031-460 Feira de Santana, BA, Brasil.<noelicarvalho@bol.com.br>.

${ }^{3}$ Departamento de Ciências Biológicas da Universidade Estadual de Feira de Santana, Unidade Experimental Horto Florestal, BR 116, km 03, 44031-460 Feira de Santana, BA, Brasil.
} 


\section{INTRODUÇÃO}

Em geral, plantas cultivadas sob elevados níveis de radiação solar possuem algumas características morfofisiológicas em comum, quando comparadas com as plantas cultivadas sob sombra: menor área foliar, aumento da espessura foliar e menor área foliar específica, maior alocação de biomassa para as raízes, maiores teores de clorofila por área foliar, maiores razões entre clorofilas $a$ e $b$ e maior densidade estomática (BOARDMANN, 1977; GIVINISH, 1988).

Modificações nos níveis de luminosidade a que uma espécie está adaptada pode, dessa forma, acarretar diferentes respostas em suas características fisiológicas, bioquímicas, anatômicas e de crescimento. Assim, a eficiência do crescimento pode estar relacionada à habilidade de adaptação das plantas às condições de intensidade luminosa do ambiente (FERREIRA et al., 1977; ENGEL, 1989; KOZLOWSKI et al., 1991; ATROCH et al., 2001).

Várias características constituem parâmetros para avaliar as respostas de crescimento de plantas à intensidade luminosa. Dentre essas, a de uso mais freqüente é a altura da planta, visto que a capacidade em crescer rapidamente quando sombreadas é um mecanismo de adaptação das plantas, compreendendo uma valiosa estratégia para escapar do sombreamento (MORAES NETO et al., 2000).

Pouco se conhece sobre as respostas fisiológicas de espécies nativas do semi-árido aos diferentes fatores do ambiente, especialmente a luz. Este trabalho teve como objetivo avaliar o crescimento inicial de plantas de licuri (Syagrus coronata (Mart.) Becc.) submetidas a diferentes níveis de luminosidade.

\section{MATERIAL E MÉTODOS}

O experimento foi conduzido na Unidade Experimental Horto Florestal - Universidade Estadual de Feira de Santana, no Município de Feira de Santana, Bahia.

Foram utilizadas plantas de licuri (Syagrus coronata (Mart.) Becc.) de aproximadamente cinco meses de idade, cultivadas em sacos de polietileno preto $(20 \mathrm{~cm} \mathrm{x} 28$ $\mathrm{cm}$ ) contendo terra + adubo orgânico (esterco curtido de gado) (3:1) como substrato.

As plantas foram submetidas a níveis de $30 \%$ (obtido cultivando as plantas em viveiro coberto com tela sombrite) e $100 \%$ (plantas a pleno sol) de intensidade luminosa. Durante a condução do experimento, as regas foram realizadas diariamente, mantendo sempre a capacidade de campo do substrato para todos os tratamentos.

O número de folhas, o diâmetro do colo e a altura das plantas foram medidos mensalmente. O número de folhas foi obtido através da contagem direta de folhas totalmente expandidas por planta. $\mathrm{O}$ diâmetro do colo foi medido com um paquímetro com precisão de $0,05 \mathrm{~mm}$ na superfície do solo (CLEMENT e BOVI, 2000) e a altura máxima, obtida com uma régua graduada de precisão de $1 \mathrm{~mm}$ ao medir a distância da superfície do solo até o ápice da maior folha esticada na posição vertical (GARCIA e FONSECA, 1991; NODARI et al., 1999).

As avaliações das massas secas da parte aérea e raízes foram realizadas no final do período experimental (365 dias), bem como a área foliar específica e total. A massa seca foi obtida colocando-se as plantas, separadas em parte aérea e raízes, em estufa com circulação forçada de ar a $80{ }^{\circ} \mathrm{C}$ até peso constante.

Para determinação da área foliar, retiraram-se de uma folha totalmente expandida 10 discos de área conhecida, determinando o peso da massa seca. Aárea foliar específica foi determinada através da relação entre área foliar do disco e o peso da massa seca do disco foliar. De posse da área foliar específica, a área foliar total da planta foi estimada através da relação entre área foliar específica e peso da massa seca foliar (PEREIRA e MACHADO, 1987).

Para determinação da concentração de clorofila foliar, foram retirados dois discos de área conhecida de folhas totalmente expandidas. Os discos foram imersos em $7 \mathrm{~mL}$ de dimetil-sulfóxido (DMSO) e incubados por 12 horas a $70^{\circ} \mathrm{C}$, no escuro (HISCOX e ISRAELSTAM, 1979). Após o resfriamento foram adicionados mais $3 \mathrm{~mL}$ de DMSO, perfazendo um volume final de $10 \mathrm{~mL}$. As absorbâncias das soluções de clorofila resultante foram lidas em espectrofotômetro a 648 e $665 \mathrm{~nm}$, utilizando como branco o DMSO. Os cálculos do conteúdo de clorofila foram feitos segundo equações de Barnes et al. (1992). Das mesmas folhas utilizadas para avaliação das clorofilas, foram retirados 10 discos para determinação da área foliar específica, conforme descrito anteriormente. 
O delineamento experimental utilizado para análise de crescimento foi inteiramente casualizado, sendo a unidade experimental composta por 20 plantas por tratamento, com quatro repetições.

Para o teor de clorofila foliar, a unidade experimental foi composta por quatro repetições de duas plantas. As diferenças entre as médias foram avaliadas pelo teste $\mathrm{F}$ em nível de 5 ou de $1 \%$ de significância.

\section{RESULTADOS E DISCUSSÃO}

De modo geral, as plantas de licuri (Syagrus coronata (Mart.) Becc.) apresentaram maior crescimento quando submetidas a $30 \%$ de intensidade luminosa (Quadros 1 e 2).

Em relação à massa seca total, verificou-se que as plantas de licuri submetidas a $30 \%$ de luz tiveram maior produção de massa seca quando comparadas com as mudas a pleno sol (100\% de luz) (Quadro 1).

Quadro 1 - Massa seca da raiz (g), parte aérea (g) e total (g) e razão raiz/parte aérea (R/PA) de plantas de licuri crescidas sob diferentes níveis de luz. Feira de Santana, BA, 2003

Table 1 -Dry mass of roots $(g)$, aerial parts $(g)$ and total $(g)$, and root/aerial part ratio $(R / P A)$ of licuri plants grown under different light intensity. Feira de Santana, $B A, 2003$

\begin{tabular}{ccc}
\hline Parâmetros & $100 \%$ & $30 \%$ \\
\hline Raiz & $7,41 \pm 0,66^{*}$ & $4,84 \pm 0,45$ \\
Parte aérea & $5,28 \pm 0,47$ & $9,52 \pm 1,15^{*}$ \\
Total & $12,69 \pm 1,11$ & $14,36 \pm 1,6$ \\
R/PA & $1,45 \pm 0,06^{* *}$ & $0,51 \pm 0,02$ \\
\hline
\end{tabular}

** e $*$ Significativos a 1 e $5 \%$ de probabilidade, respectivamente, pelo teste F.

Quadro 2 - Diâmetro do colo (mm), altura (cm) e número de folhas em plantas de licuri submetidas a diferentes níveis de luminosidade. Feira de Santana, BA, 2003

Table 2 -Stem diameter ( $\mathrm{mm}$ ), height ( $\mathrm{cm}$ ) and number of leaves in licuri plants subjected to different light intensities. Feira de Santana, BA, 2003

\begin{tabular}{lcc}
\hline Parâmetros & $100 \%$ & $30 \%$ \\
\hline Diâmetro & $7,77 \pm 0,33$ & $8,07 \pm 0,49$ \\
Altura & $43,48 \pm 2,16$ & $74,70 \pm 2,77^{*} *$ \\
Folhas & $4,3 \pm 0,17$ & $5,0 \pm 0,08^{*}$ \\
\hline
\end{tabular}

** e * Significativos a 1 e $5 \%$ de probabilidade, respectivamente, pelo teste F.
Resultados semelhantes foram encontrados em E. edulis Mart., em que as plantas, crescendo em luz solar plena, apresentaram redução do crescimento em massa seca, mostrando-se intolerantes a essa quantidade de luz (NAKAZONO et al., 2001). De acordo com Kitao et al. (2000), a exposição prolongada a altas irradiâncias pode ser prejudicial às plântulas, por absorverem mais fótons de luz do que podem utilizar, podendo ter como conseqüência a fotoinibição ou, mesmo, a morte da planta.

Observa-se, no Quadro 1, que a distribuição de massa seca para os diferentes órgãos da planta variou de acordo com os níveis de luminosidade. As plantas apresentaram diferenças significativas na produção de massa seca da raiz e parte aérea. A proporção de massa seca direcionada para as raízes aumentou nas plantas crescidas a $100 \%$ de luz; a parte aérea, diferentemente do sistema radicular, teve diminuição da massa seca no tratamento que recebeu maior luminosidade. Esses resultados apontam que as plantas de $S$. coronata sob o menor nível de luz (30\%) aumentaram a distribuição de massa seca na parte aérea, em detrimento do desenvolvimento do sistema radicular. Um padrão de alocação de biomassa que prioriza os órgãos aéreos sob condições de sombreamento permite maior captação de luz pelas plântulas, otimizando o processo fotossintético em um ambiente onde a luz limita a fotossíntese (CHAPIN et al., 1987).

Para a razão raiz/parte aérea, observou-se que houve tendência de redução nos valores no tratamento que recebeu menor nível de luz (Quadro 1). Segundo Claussen (1996), a razão raiz/parte aérea mais elevada em plantas de ambientes mais iluminados indicam que a biomassa distribui-se mais para as raízes que para os órgãos fotossintetizantes. Essa tendência permite maior absorção de água e nutrientes, estratégia que garantiria à planta maior capacidade de suportar as maiores taxas de fotossíntese e transpiração em ambientes mais iluminados. Bongarten e Teskey (1987) também relataram que a redução da massa seca do sistema radicular com o aumento do sombreamento se deve ao fato de as plantas crescidas a pleno sol estarem sujeitas à maior restrição hídrica, o que pode induzir o crescimento da massa seca do sistema radicular em detrimento do acúmulo de assimilados na parte aérea.

O crescimento em altura das plantas de licuri foi inversamente relacionado com o aumento da luminosidade (Quadro 2). As plantas submetidas a 30\% de luz 
apresentaram diferenças significativas no crescimento em altura, em comparação com o crescimento a pleno sol. Sob condições de $30 \%$ de luminosidade, o crescimento em altura das plantas foi aproximadamente $72 \%$ do que no cultivado a pleno sol.

A capacidade de rápido crescimento em ambiente sombreado é um mecanismo importante de adaptação da espécie, o que constitui uma valiosa estratégia para escapar às condições de baixa disponibilidade de luz (MORAES-NETO et al., 2000). Osunkoya e Ash (1991) e King (1994) relataram que o crescimento maior em altura das plantas em ambientes sombreados é uma resposta bastante comum, podendo ser atribuída a um maior investimento no alongamento celular, visando a uma busca maior de luz. Segundo Wardlaw (1990), plantas cultivadas sob condições de baixa disponibilidade de luz tentariam investir maior quantidade de fotoassimilados na parte aérea. Além disso, maior alongamento celular contribuiria para maior altura dessas espécies sob ambientes sombreados.

Quanto ao diâmetro do colo, não houve diferença significativa entre os níveis de luz, apesar de as plantas mostrarem tendência de serem maiores quando cresciam a 30\% de luminosidade (Quadro 2). À semelhança da altura, o diâmetro do colo foi superior em plantas cultivadas sob maior restrição de luz.

O número de folhas diferiu entre os tratamentos e apresentou valores significativos quando as plantas cresciam em ambientes mais sombreados (Quadro 2). A diminuição do número de folhas nas plantas submetidas a $100 \%$ de luz pode ter promovido alterações no processo fotossintético, prejudicando principalmente o crescimento em altura das plantas de licuri. De acordo com Nodari et al. (1999), o número de folhas não é a característica mais indicada para representar diferenças no crescimento de plantas quando submetidas a diferentes níveis de luz, uma vez que, continuamente, há queda e emissão de novas folhas. Mesmo assim, o número de folhas, em conjunto com as demais características avaliadas, demonstrou que o crescimento de plantas de licuri é favorecido pelo sombreamento.

Diante dos dados obtidos, acredita-se que as plantas de licuri requerem certo nível de sombreamento durante o seu crescimento inicial, pelo menos até 18 meses, sendo esse fator favorável para o seu estabelecimento a campo. Torna-se importante caracterizar o crescimento e desenvolvimento dessa espécie, especialmente em relação à luminosidade, podendo subsidiar não apenas a produção de mudas e processos relacionados à implantação de licurizais, como também o estabelecimento de estratégias de manejo com essa espécie.

Maior crescimento sob menores níveis de radiação em relação às características de crescimento estudadas também foram observadas em algumas espécies de palmeiras, como palmiteiro (E. edulis Mart.), pupunheira (Bactris gasipaes H. B. K.) e coqueiro (Cocos nucifera L.) (PINHEIRO et al., 1988; GARCIA e FONSECA, 1991; NODARI et al., 1999; TSUKAMOTO FILHO et al., 2001; FARIA et al., 2002).

As plantas de $S$. coronata apresentaram maior área foliar total quando crescidas a $100 \%$ de luminosidade. A área foliar específica (que está relacionada à espessura foliar) apresentou aumento com a redução da luminosidade (Quadro 3). Observou-se ainda que, em condições de baixa disponibilidade de luz, o aumento da área foliar específica não foi tão elevado para impedir a redução da área foliar total. Dale (1988) relatou que a área foliar das espécies que evitam o sombreamento aumenta em ambientes com maior disponibilidade de luz, ao passo que a área foliar de espécies tolerantes ao sombreamento tende a ser aumentada em condições de baixa luminosidade. Segundo Gordon (1989), quando a espécie tem capacidade adaptativa para compensar a deficiência de luz ocasionada pelo sombreamento, há aumento da área foliar, o que resulta em aumento da superfície fotossintetizante, de modo que se torna possível a absorção do máximo de luz incidente para a realização da fotossíntese. Em plantas submetidas a ambientes mais iluminados ocorre diminuição da área foliar, o que é benéfico para a planta, uma vez que menos material foliar é exposto a eventuais danos causados pelo excesso de luz (CLAUSSEN, 1996).

Quadro 3 - Área foliar específica $\left(\mathrm{cm}^{2} . \mathrm{g}^{-1}\right)$ e área foliar total $\left(\mathrm{cm}^{2}\right.$.planta $\left.{ }^{-1}\right)$ de plantas de licuri crescidas sob diferentes níveis de luz. Feira de Santana, BA, 2003

Table 3 - Specific leaf area $\left(\mathrm{cm}^{2} \cdot \mathrm{g}^{-1}\right)$ and total leaf area $\left(\mathrm{cm}^{2}\right.$.plant $\left.{ }^{-1}\right)$ of licuri plants grown under different light intensities. Feira de Santana, BA, 2003

\begin{tabular}{lcc}
\hline \multicolumn{1}{c}{ Parâmetros } & $100 \%$ & $30 \%$ \\
\hline Área foliar específica & $10,68 \pm 0,07$ & $12,08 \pm 0,32^{* *}$ \\
Área foliar total & $2,19 \pm 0,21 *$ & $1,37 \pm 0,16$ \\
\hline
\end{tabular}

$* *$ e* Significativos a 1 e $5 \%$ de probabilidade, respectivamente, pelo teste $\mathrm{F}$ 
Em relação à concentração de clorofila, as plantas submetidas a $30 \%$ de luz indicaram uma tendência de apresentar os maiores teores de clorofilas $b$ e total (Quadro 4). A razão clorofila $a / b$ foi maior nas plantas crescidas a pleno sol, embora não diferisse significativamente das plântulas crescidas sob baixa intensidade luminosa. Boardman (1977) afirmou que folhas de sombra apresentam maior concentração de clorofilas do que as de sol. Uma explicação para esse comportamento é que as plantas crescidas sob baixas radiações apresentam melhor desenvolvimento de grana; logo, o aumento relativamente maior de clorofila $b$ e sua maior correlação com a radiação. Maior proporção relativa de clorofila $b$ pode ser vantajosa sob sombreamento, permitindo maior eficiência de absorção de luz menos intensa, o que garante a taxa fotossintética (WHATLEY e WHATLEY, 1982).

Givinish (1988) e Boardman (1977) afirmaram que a proporção entre clorofilas $a$ e $b$, de maneira geral, tende a diminuir com a redução da luz, devido à maior proporção relativa de clorofila $b$ em ambiente sombreado. Para as plantas de licuri, a incidência de luz total proporcionou maior razão clorofila $a / b$. Em estudos com palmiteiro (E. edulis Mart.), Nakazono et al. (2001) verificaram que os teores de clorofila $a$ e $b$ foram menores quanto maior a quantidade de luz, enquanto a razão entre elas foi crescente. Paulilo (2000), em estudos com a mesma espécie, verificou aumento no teor de clorofila total e clorofila $b$ em plantas sob baixos níveis de radiação.

Observa-se, no Quadro 4, que a área foliar específica nas folhas em que se avaliou a clorofila foi significativamente maior sob condições de $30 \%$ de luz, o mesmo acontecendo com relação ao teor de clorofila total. Segundo Boardman (1977), a maior concentração de clorofila, tanto por unidade de massa quanto por unidade de área foliar em ambientes de baixa irradiância, pode indicar que o aumento no conteúdo de clorofila foi grande o suficiente para impedir a sua diluição ao longo de uma área foliar maior. Esse aumento na concentração de clorofilas pode representar maior investimento nos pigmentos responsáveis pela absorção da luz. Maior superfície foliar com maior espessura do parênquima paliçádico (maior AFE) acarreta, muitas vezes, maior concentração de clorofila por unidade de área foliar. Esse efeito pode promover uma absorção de luz mais eficiente sob baixa intensidade de luz e prover contra efeitos fotodestrutivos em intensidades de luz altas (CLAUSSEN, 1996).
Quadro 4 - Concentração de clorofilas $a, b$ e total (ìg/ $\left./ \mathrm{cm}^{2}\right)$, razão clorofila $a / b(\mathrm{Cl} a / \mathrm{Cl} b)$ e área foliar específica (AFE) $\left(\mathrm{cm}^{2} \cdot \mathrm{g}^{-1}\right)$ em folhas de licuri submetidas a diferentes níveis de luminosidade. Feira de Santana, BA, 2003

Table 4-Chlorophyll a, b and total concentration (ig/ $\left.\mathrm{cm}^{2}\right)$, chlorophyll a/b ratio $(\mathrm{Cl} \mathrm{a} / \mathrm{Cl} \mathrm{b})$ and specific leaf area $(A F E)\left(\mathrm{cm}^{2} \cdot \mathrm{g}^{-1}\right)$ in licuri leaves subjected to different light intensities. Feira de Santana-BA, 2003

\begin{tabular}{lcc}
\hline Parâmetros & $100 \%$ & $30 \%$ \\
\hline Clorofila $a$ & $31,49 \pm 3,45$ & $30,52 \pm 2,52$ \\
Clorofila $b$ & $17,62 \pm 0,71$ & $22,53 \pm 0,99^{* *}$ \\
Clorofila total & $49,10 \pm 3,72$ & $53,05 \pm 3,06$ \\
Cl $a$ / Cl $b$ & $1,81 \pm 0,16$ & $1,40 \pm 0,11$ \\
AFE & $11,24 \pm 0,23$ & $12,72 \pm 0,27 * *$ \\
\hline
\end{tabular}

** Significativo a $1 \%$ de probabilidade, respectivamente, pelo teste $\mathrm{F}$.

\section{CONCLUSÕES}

A utilização de diferentes níveis de luminosidade para as plantas de licuri em fase inicial de desenvolvimento demonstrou que os melhores índices de crescimento estão relacionados com o sombreamento, e a exposição das mudas a pleno sol pode inibir o crescimento das plantas.

O sombreamento favoreceu o crescimento das plantas de licuri, pelo menos até 18 meses de idade, fato importante para seu estabelecimento a campo e definição de estratégias de manejo.

\section{REFERÊNCIAS BIBLIOGRÁFICAS}

ATROCH, E. M. A. C. et al. Crescimento, teor de clorofilas, distribuição de biomassa e características anatômicas de planas jovens de Bauhinia forficata Link submetidas a diferentes condições de sombreamento. Ciência

Agrotecnologia, v. 25, n. 4, p. 853-862, 2001.

BARNES, I. D. et al. A reapprausal of the use of DMSO for the extraction and determination of chlorophylls $a$ and $b$ in lichens and higher plants. Enviromental and Experimental Botany, v. 32, n. 2, p. 83-100, 1992.

BOARDMANN, N. K. Comparative photosynthesis of sun and shade plants. Annual Rewiew of Plant Physiology, v. 28,p. 355-377, 1977.

R. Árvore, Viçosa-MG, v.30, n.3, p.351-357, 2006 
BONGARTEM, B. C.; TESKEY, R. O. Dry weight partitioning and its relationships to productivity in loblolly pine seedling from seven sources.

Forest Science, v. 33, n. 3, p. 255-267, 1987.

CHAPIN, F. S. et al. Plant responses to multiple environmental factors. BioScience, v. 37, n. 1, p. 49-57, 1987.

CLAUSSEN, J. W. Acclimation abilities of three tropical rainforest seedlings to an increase in light intensity. Forest Ecology and

Management, v. 80, p. 245:255, 1996.

CLEMENT, C. R. \& BOVI, M. L. A. Padronização de medidas de crescimento e produção de experimentos com pupunheira para palmito. Acta Amazônica, v. 30, n. 3, p. 349-362, 2000.

DALE, J. E. The control of leaf expansion. Annual Review of Plant Physiology, v. 39, p. 267-295, 1988.

ENGEL, V. L. Influência do sombreamento sobre o crescimento de mudas de essências nativas, concentração de clorofila nas folhas e aspectos de anatomia. 1989. 202f. Dissertação (Mestrado em Ciências Florestais) - Escola Superior de Agricultura Luiz de Queiroz, Piracicaba, 1989.

FARIA, W. S.; GAÍVA, H. N.; PERIRA, W. E. Comportamento de cinco genótipos de coqueiro (Cocos nucifera L.) na fase de germinação e de crescimento de mudas, sob diferentes sistemas de produção. Revista Brasileira de

Fruticultura, v. 24, n. 2, p. 458-462, 2002.

FEREIRA, M. G. M. et al. Efeito do sombreamento na produção de mudas de quatro espécies florestais nativas. Revista Árvore, v. 1, n. 2, p. 121-134, 1977.

GARCIA, T. B.; FONSECA, C. E. L. Crescimento de mudas de pupunheira em condições de viveiro coberto com palha. Pesquisa Agropecuária Brasileira, v. 26, n. 9, p. 1447-1451, 1991.

GIVINISH, T. J. Adaptation to sun and shade: a whole-plant perspective. Australian Journal of Plant Physiology, v. 15, p. 63-92, 1988.
GORDON, J. C. Effect of shade on photosynthesis and dry weight distribution in yellow birch (Betula alleghaniensis Britton) seedlings. Ecology, v. 50, n. 5, p. 924-926, 1989.

HISCOX, J. D.; ISRAESLTAM, G. F. A metod for extration of chlorophyll from leaf without maceration. Canadian Journal of Botany, v. 57, p. 1332-1334, 1979.

KING, D. Influence of light level on the growth and morphology of saplings in a Panamanian forest. American Journal of Botany, v. 81, n. 8, p. $948-957,1994$.

KITAO, M. et al. Susceptibility to photoinhibition of three deciduous broadleaf tree species with different successional traits raised under various light regimes. Plant, Cell and Environment, n. 23, p.81-89, 2000.

KOZLOWSKI, T.; KRAMER, P. J.; PALLARDY, S. G. The physiological ecology of woody plants. London: Academic Press, 1991. 657p.

MORAES NETO, S. P. et al. Crescimento de mudas de algumas espécies arbóreas que ocorrem na mata atlântica, em função do nível de luminosidade. Revista Árvore, v. 24, n. 1, p.35-45, 2000.

NAKAZONO, E. M. et al. Early growth of Euterpe edulis Mart. in different light enviroments. Revista Brasileira de Botânica, v. 24, n. 2, p. 173-179, 2001.

NODARI, R. O. et al. Crescimento de mudas de palmiteiro (Euterpe edulis Mart.) em diferente condições de sombreamento e densidade.

Revista Árvore, v. 23, n. 3, p. 285-292, 1999.

OSUNKOYA. O. A.; ASH, J. E. Acclimation to a change in light regime in seedlings of six Australian rainforest tree species. Australian Journal of Botany, v. 39, p. 591-605, 1991.

PAULILO, M. T. S. Ecofisiologia de plântulas e plantas jovens de Euterpe edulis Mart.

(Arecaceae): Comportamento em relação à variação da radiação solar. Sellowia, v. 49-52, p. 93-105, 2000. 
PEREIRA, A. R.; MACHADO, E. C. Análise quantitativa do crescimento de comunidades vegetais. Campinas: Instituto Agronômico de Campinas, 1987. (Boletim Técnico, 114).

PINHEIRO, G. S.; MARIANO, G.; CRESTANA, C. S. M. Estudo do desenvolvimento do palmiteiro Euterpe edulis Mart.

(Palmae), sob diversas condições de sombreamento, em plantio de Pinus kesiya Royle ex Gordon. São Paulo: Instituto Florestal, 1988. p. 171-180 (Boletim Técnico, 42).
TSUKAMOTO FILHO, A. A. et al. Aspectos fisiológicos e silviculturais do palmiteiro (Euterpe edulis Martius) plantados em diferentes tipos de consórcio no município de Lavras, Minas Gerais. Cerne, v. 7, n. 1, p. 41-53, 2001.

WARDLAW, I. F. The control of carbon partitioning in plantas. New Phytologist, n. 116, p. 341-381, 1990.

Whatley, J. M.; Whatey, F. R. A luz e a vida das plantas. São Paulo: EDUSP, 1982. 102 p. 